\title{
RELEVANSI PENDIDIKAN KARAKTER DALAM PERSPEKTIF FILSAFAT AL-GHAZALI
}

\author{
Amiruddin Hadi Wibowo \\ Sekolah Tinggi Ilmu Al-Qur'an dan Sains Al-Ishlah (STIQSI) \\ Sendangagung Paciran Lamongan \\ Email: udinhoshi@gmail.com
}

\begin{abstract}
Abstrak
Pendidikan di Indonesia pada abad ke-21 dihadapkan pada sejumlah peluang dan tantangan yang berbeda dengan zaman-zaman sebelumnya. Oleh sebab itu, diperlukan langkah antisipasi untuk menyesuaikan diri dengan berbagai tuntutan dan dinamika perubahan yang sedang dan akan terus berlangsung. Bangsa Indonesia selayaknya senantiasa mengasah kemampuan yang dibutuhkan dalam menghadapi berbagai perubahan, salah satunya pada bidang pendidikan yang mungkin akan terjadi dengan sangat revolusioner. Pendidikan karakter penting diimplementasikan karena lebih menitikberatkan pada kualitas tindakan, perbuatan, atau perilaku manusia. Pada implementasi pendidikan karakter, terdapat relevansi erat dengan konsep pendidikan akhlak (karakter) dalam filsafat al-Ghazali. Konsep pendidikan karakter dalam kajian pemikiran alGhazali dalam kitab Ayyuhal Walad sangat relevan dengan tujuan pendidikan karakter itu sendiri, yaitu tumbuhnya nilai-nilai moral dalam pribadi anak. Tulisan ini akan menganalisis pandangan filsafat akhlak al-Ghazali dan relevansinya dengan urgensi pendidikan karakter pada abad ke-21.
\end{abstract}

Kata Kunci: al-Ghazali, Filsafat, Pendidikan Karakter

\section{A. Pendahuluan}

Dalam Undang-Undang Nomor 20 Tahun 2003 tentang Sistem Pendidikan Nasional (UUSPN) pasal 3 dijelaskan bahwa "Pendidikan nasional berfungsi mengembangkan kemampuan dan membentuk watak serta peradaban bangsa yang bermartabat dalam rangka mencerdaskan kehidupan bangsa, bertujuan untuk berkembangnya potensi peserta didik agar menjadi manusia yang beriman dan bertaqwa kepada Tuhan Yang Maha Esa, berakhlak mulia, sehat, berilmu, cakap, kreatif, mandiri, dan menjadi warga negara yang demokratis serta bertanggung jawab". Pasal 1 UU tersebut juga menjelaskan bahwa pendidikan adalah "Usaha sadar dan terencana untuk mewujudkan suasana belajar dan proses pembelajaran agar peserta didik secara aktif mengembangkan potensi dirinya untuk memiliki kekuatan spiritual 
keagamaan, pengendalian diri, kepribadian, kecerdasan, akhlak

mulia, serta ketrampilan yang diperlukan dirinya, masyarakat, bangsa, dan Negara". ${ }^{1}$ Rumusan tujuan pendidikan nasional tersebut mencerminkan gambaran umum sosok manusia Indonesia yang diharapkan dan wajib dihasilkan melalui penyelenggaraan setiap program pendidikan. Oleh karena itu, rumusan tujuan pendidikan nasional menjadi dasar dalam pengembangan pendidikan karakter di sekolah dengan berlandaskan pada Pancasila, UUD 1945 dan kebudayaan bangsa Indonesia.

Pendidikan pada hakikatnya memiliki dua tujuan, yaitu membantu manusia untuk menjadi cerdas dan pintar (smart), dan membantu mereka menjadi manusia yang baik dan berakhlak $($ good $) .{ }^{2}$ Lebih mudah menjadikan manusia pintar dan cerdas daripada menjadikan manusia yang bijak dan berakhlak baik. Dengan demikian, permasalahan akhlak atau moral pada saat ini merupakan persoalan fundamental yang mengiringi kehidupan manusia di manapun dan kapanpun.

Kenyataan tentang problem moral inilah yang kemudian merujuk pada pentingnya penyelenggaraan pendidikan karakter. Menurunnya kualitas moral dalam kehidupan manusia Indonesia dewasa ini, terutama di kalangan siswa, menjadikan Pendidikan karakter urgen untuk digaungkan. Istilah pendidikan karakter muncul pada beberapa dekade terakhir di Amerika Serikat kemudian dua tahun terakhir ini digunakan di Indonesia. Seperti dinyatakan Suyata, ${ }^{3}$ istilah pendidikan karakter lebih populer di kawasan Asia, sedangkan istilah pendidikan moral lebih masyhur di Amerika. Sementara itu, di Inggris orang lebih menyukai penggunaan istilah pendidikan nilai. Pendidikan budi pekerti dan pendidikan moral Pancasila secara khusus dipergunakan di Indonesia.

Merujuk pada problem moral dan pentingnya pendidikan karakter dapat

\footnotetext{
1 Depdiknas, Undang-Undang Nomor 20 Tahun 2003 tentang Sistem Pendidikan Nasional (Depdiknas: 2003), 3, www.depdiknas.go.id , diakses tanggal 11 Mei 2020

2 Ajat Sudrajat, "Mengapa Pendidikan Karakter?,". Jurnal Pendidikan Karakter, Vol I, No. 1, (Oktober, 2011), 47

${ }^{3}$ Suyata, "Pendidikan Karakter: Dimensi Filosofis" dalam Pendidikan Karakter dalam Perpektif Teori dan Praktik, ed. Darmiyati Zuchdi, (Yogyakarta: UNY Press, 2011), 13.
} 
dilihat dari kasus moral yang pernah menimpa kedua putra Nabi Adam AS. ${ }^{4}$ Perilaku Qabil dan Habil dalam menyedekahkan hartanya, sikap dengki Qabil terhadap Habil yang berujung pada kasus pembunuhan, dan juga banyaknya Nabi dan Rasul yang diturunkan Allah kepada umat manusia, menunjukkan akutnya problem moral ini. Nabi Muhammad saw bahkan diutus ke dunia ini oleh Allah semata-mata untuk menyempurnakan akhlak dan karakter manusia.

Dewasa ini, sedang hangat dibicarakan tentang pendidikan karakter yang menjadi basis pendidikan. Akan tetapi, sebagian besar mengkaji pendidikan karakter yang dipromosikan oleh Thomas Lickona maupun Lawrence Kohlberg. Pada sudut pandang yang berbeda, kajian teoritis pada artikel ini difokuskan pada pengkajian relevansi Pendidikan karakter dengan pemikaran filsuf al-Ghazali. Pemikirannya tentang pendidikan akhlak banyak dijumpai karya fenomenal Al- Ghazali kitab Ihya Ulumuddin. Tokoh muslim besar ini sangat berjasa membangun dan mengembangkan ilmu akhlak dalam agama Islam.

Dengan demikian kajian mengenai pendidikan karakter dan implementasinya menurut al-Ghazali menjadi sangat penting. Harapannya dapat ditemukan pokok- pokok poin utama sebagai landasan dan acuan dalam pengembangan pendidikan sebagaimana yang diharapkan oleh Islam. Yakni untuk membentuk pribadi muslim yang mendekati kepada kesempurnaan dengan cara internalisasi pendidikan karakter yang berlandaskan akhlakul karimah.

\section{B. Pendidikan Karakter}

Secara terminologis 'karakter' diartikan sebagai sifat yang ada pada diri manusia yang bergantung pada faktor kehidupannya sendiri. Hidayatullah ${ }^{5}$ menjelaskan secara harfiah bahwa 'karakter' adalah akhlak atau budi pekerti individu yang berkualitas serta bermoral. Menurut kamus lengkap Bahasa Indonesia, ${ }^{6}$ karakter adalah akhlak, budi pekerti yang membedakan seseorang

\footnotetext{
4 Ali Shariati, Tugas Cendekiawan Muslim, diterjemahkan oleh M. Amien Rais (Jakarta: Srigunting, 1996), 34

5 Hidayatullah, M. Furqon, Guru Sejati: Pengembangan Insan Berkarakter Kuat dan Cerdas, (Surakarta: Yuma Pustaka, 2010).

${ }^{6}$ Tim Bahasa Pustaka Agung Harapan, Kamus Cerdas Bahasa Indonesia Terbaru, (Surabaya: CV Pustaka Agung Harapan, 2003), 300
} 
dari yang lain, tabiat, watak. Sedangkan menurut ahli psikologi, karakter adalah sebuah sistem kebiasaan yang mengarahkan tindakan seorang individu untuk berprilaku dan berbuat. Dengan demikian, jika karakter seseorang dapat diamati, maka dapat diamati pula bagaimana individu tersebut akan bersikap untuk kondisi-kondisi tertentu. Sehingga dapat ditarik sebuah poin bahwa karakter dan akhlak tidak memiliki perbedaan yang signifikan. Keduanya didefinisikan sebagai suatu tindakan yang disebut dengan kebiasaan.

Karakter dimaknai sebagai cara berfikir dan berperilaku yang khas tiap individu, baik dalam lingkup keluarga, masyarakat, bangsa, dan negara. Individu yang mempunyai karakter baik adalah individu yang dapat membuat keputusan dan siap mempertanggung jawabkan. Karakter dapat dianggap sebagai nilai-nilai perilaku manusia yang berhubungan dengan diri sendiri, Tuhan Yang Maha Esa, sesama manusia, dan lingkungan yang terwujud dalam pikiran, sikap, perasaan, perkataan, dan perbuatan berdasarkan norma-norma yang berlaku. ${ }^{7}$

Dengan demikian karakter merupakan perpaduan antara moral, etika, dan akhlak. Moral lebih menitik beratkan pada kualitas tindakan, perbuatan, atau perilaku manusia. Sebaliknya, etika memberikan penilaian tentang baik dan buruk, berdasarkan norma-norma yang berlaku dalam masyarakat tertentu. Sedangkan akhlak tatanannya lebih menekankan bahwa pada hakikatnya dalam diri manusia itu telah tertanam keyakinan di mana keduanya (baik dan buruk) ada. Oleh karena itu, pendidikan karakter dimaknai sebagai pendidikan akhlak, pendidikan nilai, pendidikan moral, dan pendidikan budi pekerti, yang tujuannya mengembangkan kemampuan siswa untuk memberikan keputusan baik-buruk dan mewujudkan kebaikan itu dalam kehidupan sehari-hari dengan sepenuh hati.

\section{Implementasi Pendidikan Karakter dalam Abad 21}

Pendidikan di Indonesia pada abad ke-21 ini dihadapkan dengan sejumlah peluang dan tantangan yang tentunya berbeda dengan zaman-zaman sebelumnya. Guna mengantisipasi dan menyesuaikan diri dengan berbagai

\footnotetext{
7 Samani, M., \& Hariyanto, Konsep dan Model Pendidikan Karakter, (Bandung: Remaja Rosdakarya, 2013), 41-42
} 
tuntutan dan dinamika perubahan yang sedang dan akan terus berlangsung, bangsa Indonesia harus semakin mengasah kemampuan yang dibutuhkan untuk menghadapi setiap revolusi pada pendidikan di abad ke-2. ${ }^{89}$

Pendidikan nasional di abad ke-21 bertujuan untuk mewujudkan cita-cita bangsa, yaitu masyarakat bangsa Indonesia yang sejahtera dan bahagia, dengan kedudukan terhormat dan setara dengan bangsa-bangsa lain di tingkat global. Cita- cita tersebut bisa diwujudkan melalui pembentukan masyarakat yang berkarakter. Dengan demikian penanaman Pendidikan karakter sejak dini merupakan salah satu langkah penting sebagai pondasi dasar mencetak generasi bangsa yang berbudi baik.

Pembentukan karakter anak dimulai dari usia 0-8 tahun. ${ }^{10}$ Artinya di masa usia tersebut karakter anak masih dapat berubah-ubah tergantung dari pengalaman hidupnya. Oleh karena itu membentuk karakter anak harus dimulai sedini mungkin bahkan sejak anak itu dilahirkan, karena berbagai pengalaman yang dilalui oleh anak semenjak perkembangan pertamanya, mempunyai pengaruh yang sangat besar. Berbagai pengalaman yang telah dialami anak berpengaruh terhadap pembentukan karakter diri anak secara utuh. Karakter yang terbentuk pada diri anak memerlukan suatu tahapan yang dirancang secara sistematis dan berkelanjutan. Sebagai individu yang sedang berkembang, anak memiliki sifat suka meniru tanpa mempertimbangkan baik atau buruk. Hal ini didorong oleh rasa ingin tahu dan ingin mencoba sesuatu yang diminati, yang kadang muncul secara spontan. Sikap jujur yang menunjukkan kepolosan seorang anak merupakan ciri yang juga dimiliki anak. Sifat unik tersebut menunjukkan bahwa anak merupakan sosok individu yang kompleks yang memiliki perbedaan dengan individu lainnya

Lickona $^{11}$ menjelaskan ada tiga hal pembentukan karakter yang perlu diintegrasikan. Pertama, knowing the good, artinya anak mengerti baik dan

\footnotetext{
${ }^{8}$ Koesoema, A. Dony, Pendidikan Karakter: Strategi Mendidik Anak di Zaman Global, (Jakarta: Grasindo, 2007).

9 Sulistiwati, Endah, Implementasi Kurikulum Pendidikan Karakter, (Yogyakarta: PT Aji Citra Parama, 2012)

10 Arismantoro, Tinjauan Berbagai Aspek Character Building Bagaimana Mendidik Anak Berkarakter, (Yogyakarta: Tiara Wacana, 2008)

11 Lickona, Thomas, Educating for Character: How Our School Can Teach Respect andResponsibility, (New York: Bantam Books, 1991).
} 
buruk, mengerti tindakan yang harus diambil dan mampu memberikan prioritas hal-hal yang baik. Membentuk karakter anak tidak hanya sekedar tahu mengenai hal-hal yang baik, namun mereka harus dapat memahami kenapa perlu melakukan hal tersebut. Kedua, Feeling the good, artinya anak mempunyai kecintaan terhadap kebajikan dan membenci perbuatan buruk. Konsep ini membangkitkan rasa cinta anak untuk melakukan perbuatan yang baik. Pada tahap ini anak dilatih untuk merasakan efek dari perbuatan baik yang dia lakukan. Sehingga jika kecintaan ini sudah tertanam maka hal ini akan menjadi kekuatan yang luar biasa dari dalam diri anak untuk melakukan kebaikan dan mengurangi perbuatan negatif. Ketiga, active the good, artinya anak mampu melakukan kebajikan dan terbiasa melakukannya. Pada tahap ini anak dilatih untuk melakukan perbuatan baik sebab tanpa anak melakukan apa yang sudah diketahui atau dirasakan.

Sementara itu, IHF (Indonesia Heritage Foundation), ${ }^{12}$ pada tahun 2004 telah menyusun komponen-komponen karakter ke dalam serangkaian nilai, yang selayaknya diajarkan kepada anak-anak. Diantaranya meliputi (1) cinta kepada Tuhan dan segenap ciptaan-Nya; (2) kemandirian dan tanggung jawab; (3) kejujuran atau amanah dan bijaksana; (4) hormat dansantun; (5) dermawan, suka menolong, dan gotong-royong; (6) percaya diri, kreatif, dan pekerja keras; (7) kepemimpinan dan keadilan; (8) baik dan rendah hati, serta (9) toleransi, kedamaian, dan kesatuan.

Sejalan dengan hal tersebut, nilai-nilai karakter pada pembelajaran abad21 harunya diimplementasikan dalam pembelajaran. Terdapat 18 nilai karakter yang diimplementasikan dalam pembelajaran. Diantaranya yaitu religius, semangat kebangsaan, jujur, cinta tanah air, toleransi, menghargai prestasi, disiplin, bersahabat/komunikatif, kerja keras, cinta damai, kreatif, gemar membaca, mandiri, peduli lingkungan, demokratis, peduli sosial, rasa ingin tahu, dan tanggung jawab. ${ }^{13}$ Dengan demikian implementasi pendidikan karakter di abad 21 bertujuan untuk meningkatkan mutu penyelenggaraan di sekolah yang mengarah pada pencapaian pembentukan karakter atau akhlak

\footnotetext{
${ }^{12}$ Megawangi, R, Pendidikan Karakter: Solusiyang Tepat untuk Membangun Karakter Bangsa, (Jakarta: Penerbit IHF [Indonesia Heritage Foundation], 2004).

${ }^{13}$ Kemendiknas, Membangun Budaya dan Karakter Bangsa, (Jakarta: Puskur, 2010), 9-10
} 
mulia siswa secara terpadu, utuh, dan (balanced) seimbang. Melalui pendidikan karakter diharapkan siswa mampu secara mandiri menggunakan dan meningkatkan pengetahuannya, serta mengkaji nilai-nilai karakter yang telah tertanam sehingga terwujud dalam perilaku yang baik dalam kehidupan sehari-hari.

\section{Konsep Pendidikan Akhlak Menurut al-Ghazali}

Di dalam buku Ihya' Ulumuddin, al-Ghazali menyatakan bahwa akhlak berkaitan dengan kata al-khalqu (kejadian) dan al-khuluqu (akhlak atau tingkah laku). Baik al-khalqu dan al-khuluqu (baik kejadian dan akhlaknya) berarti baik lahir dan batin. Karena yang dimaksud dengan al-khalqu adalah bentuk lahir dan al-khuluqu adalah bentuk batin. Hal ini berkaitan dengan keadaan manusia yang tersusun dari jasad (tubuh) yang terlihat mata dan diraba serta unsur roh dan jiwa yang hanya dapat dilihat dengan mata hati. Dari dua unsur tersebut, unsur roh dan jiwa lebih besar nilainya dibanding dengan tubuh yang terlihat dengan mata kepala. ${ }^{14}$

Adapun yang dimaksud akhlak adalah keadaan jiwa yang menetap dan dari padanya terbit semua perbuatan dengan mudah tanpa memerlukan pemikiran dan penelitian. Bila terbit dari jiwa perbuatan-perbuatan baik dan terpuji berarti ia akhlak yang baik. Sebaliknya bila yang terbit dari padanya perbuatan-perbuatan jelek, maka dinamakan dengan akhlak yang buruk. ${ }^{15}$ Sejalan dengan itu, berarti seseorang yang memberi bantuan hanya karena keinginan yang muncul secara tiba- tiba saja, maka orang itu tidak dapat dikatakan pemurah, karena sifat tersebut belum tetap pada jiwanya. Demikian pula bila seseorang memberi bantuan karena tekanan moral atau tidak memberi ketidakadilan dan rasa marah, maka orang itu juga belum dapat dikatakan mempunyai watak pemurah dan penyantun. ${ }^{16}$

Al-Ghazali dikenal sebagai ulama besar muslim yang intelektual dan sangat mencintai ilmu pengetahuan. Kecintaannya pada ilmu pengetahuan membentuknya menjadi piawai dalam beragam bidang keilmuan, sehingga menjadikannya salah satu dari beberapa tokoh Islam yang paling besar

\footnotetext{
${ }^{14}$ Al-Ghazali, Ihya' Ulum ad-Din, (Beirut: Dar Ibnu Hazm, 2005).

15 Al-Ghazali, Ihya' Ulum al-Dien, (Jakarta: Fauzan, 1983).

${ }^{16}$ Al-Madjidi, Konsep Pendidikan Para Filosof Muslim, (Jogyakarta: Al-Amin, 1997).
} 
pengaruhnya dalam sejarah Islam. Hal tersebut karena banyaknya konstribusi beliau dalam mengembangkan ilmu Islam yang diwujudkan dalam banyaknya buku karya beliau, dari beberapa keilmuan yang ditulis dalam buku nya beliau banyak mengkaji tentang akhlak.

Pendidikan akhlak dalam konsep al-Ghazali tidak hanya terbatas pada apa yang dikenal dengan teori menengah saja. Akan tetapi meliputi sifat keutamaannya yang bersifat pribadi, akal dan amal perorangan dalam masyarakat. Atas dasar itulah, Pendidikan akhlak menurut al-Ghazali memiliki tiga dimensi diantaranya adalah (1) dimensi diri, yakni orang dengan dirinya dan tuhan; (2) dimensi sosial, yakni masyarakat, pemerintah dan pergaulan dengan sesamanya; dan (3) dimensi metafisik, yakni akidah dan pegangan dasar. ${ }^{17}$

Selanjutnya al-Ghazali mengklasifikasikan pendidikan akhlak yang terpenting dan harus diketahui meliputi (1) perbuatan baik dan buruk, (2) kesanggupan untuk melakukannya, (3) mengetahui kondisi akhlaknya, dan (4) sifat yang cenderung kepada satu dari dua hal yang berbeda, dan menyukai salah satu diantara keduanya, yakni kebaikan atau keburukan. ${ }^{18}$ Dari beberapa keterangan diatas dapat difahami bahwa pendidikan akhlak menurut alGhazali adalah suatu usaha untuk menghilangkan semua kebiasaan-kebiasaan jelek yang telah dijelaskan oleh syariat secara terperinci, hal-hal yang harus dijauhi oleh manusia, sehingga akan terbiasa dengan akhlak-akhlak yang mulia.

Jika ada 18 nilai karakter yang di implementasikan dalam pembelajaran oleh kemendiknas, maka pendidikan nilai karakter menurut Imam al-Ghazali dalam kitab Ayyuhal Walad dikelompokkan menjadi dua. Diantaranya yaitu nilai individu dan nilai kolektif/sosial. Pertama, nilai individu yang terdiri dari nilai religius. Religius yakni sikap dan perilaku yang patuh dalam melaksanakan ajaran agama yang dianutnya. Religius berarti mengadakan hubungan dengan sesuatu yang Adi Kodrati, hubungan antara makhluk dengan Sang Kholik. Hubungan ini mewujud dalam sikap batinnya serta

\footnotetext{
${ }^{17}$ Daudy, Achmad, Kuliah Filsafat Islam, (Jakarta: Bintang Bulan, 1986).

${ }^{18}$ Al-Ghazali, Al-Munziq min al-Dhalal, (Beirut: Maktabah al-Sya'ibah, 1960).
} 
tampak dalam ibadah yang dilakukannya dan tercermin pula dalam kesehariannya. ${ }^{19}$ Kedua yaitu nilai kolektif/sosial yang terdiri dari peduli sosial, tanggung jawab, kerja keras, dan menghargai prestasi. ${ }^{20}$

Kitab Ayyuhal Walad yang ditulis oleh Imam al-Ghazali merupakan kitab yang lebih menekankan pada pendidikan akhlak terhadap anak didik yang bertujuan untuk menyempurnakan akhlak, dan mengandung makna yang tinggi. Dengan demikian pendidikan akhlak menurut Imam al-Ghazali dapat diimplementasikan dalam pembelajaran. Apabila akhlak terpuji tertanam dalan jiwa setiap orang pasti akan tercipta sesuatu kehidupan yang aman, tentram dan damai.

\section{E. Relevansi Pendidikan Karakter dalam Filsafat al-Ghazali}

Dalam pendidikan Nasional mempunyai tujuan yang tertera dalam UU Nomor 20 Tahun 2003 pasal 3 yaitu tentang sistem pendidikan nasional. ${ }^{21} \mathrm{Di}$ dalamnya disebutkan bahwa pendidikan nasional berfungsi membentuk watak dan mengembangkan kemampuan bangsa yang bermartabat dalam rangka mencerdaskan kehidupan bangsa agar menjadi manusia yang beriman dan bertaqwa kepada Tuhan Yang Maha Esa, berakhlak mulia, berlimu, sehat, kreatif, mandiri serta menjadi warga Negara yang demokratis dan bertanggung jawab.

Tujuan pendidikan nasional yang telah dijabarkan tidak jauh berbeda dengan tujuan pendidikan yang disebutkan oleh Imam al-Ghazali, namun Imam Al- Ghazali lebih menekankan pada syariah dan agama karena lebih mendekatkan manusia kepada Sang Pencipta. Tujuan pendidikan menurut Imam al-Ghazali yaitu lebih mengarah kepada realisasi tujuan keagamaan dan akhlak, dimana taqorrub dan fadhilah (keutamaan) kepada Allah yang merupakan tujuan paling penting dalam pendidikan.

Pendidikan karakter dalam sudut pandang Islam secara teoretik telah ada sejak Islam diturunkan di dunia, seiring dengan diutusnya para Nabi untuk memperbaiki dan menyempurnakan akhlak (karakter) manusia. Penggagas

\footnotetext{
${ }^{19}$ Shihab, Quraish, Membumikan al-Qur'an, (Bandung: Mizan, 1992).

${ }^{20}$ Zubaedi, Desain Pendidikan Karakter, (Jakarta: Kencana, 2012).

${ }^{21}$ Undang-undang Nomor 20 Tahun 2003, Tentang Sistem Pendidikan Nasional dan Penjelasannya, (Yogyakarta: Media Wacana Pers)
} 
pendidikan karakter dalam masyarakat Muslim sekarang adalah Nabi Muhammad saw, seorang teladan bagi umat manusia. Tidak ada satu orang pun di dunia yang berkarakter semulia Nabi Muhammad.

Imam al-Ghazali merupakan ulama yang produktif dalam menulis. Secara garis besar karangan Imam al-Ghazali terbagi dalam empat bidang, yakni Ilmu Kalam, Falsafah, Batiniyah, Tassawuf. Dari sebagian banyak buku Imam al-Ghazali yang terkenal diantaranya adalah Muqisdul Falasifah, Tahafutul Falasifah, Al Munqidz Minandh Dhalal dan Ihya' Ulumudin. ${ }^{22}$ Imam alGhazali terkenal dengan filsafatnya yang merujuk pada Pendidikan akhlak yang relevan dengan pendidikan karakter. Berikut akan dijabarkan dalam bagan relevansi pendidikan karakter dengan aliran filsafat al-Ghazali.

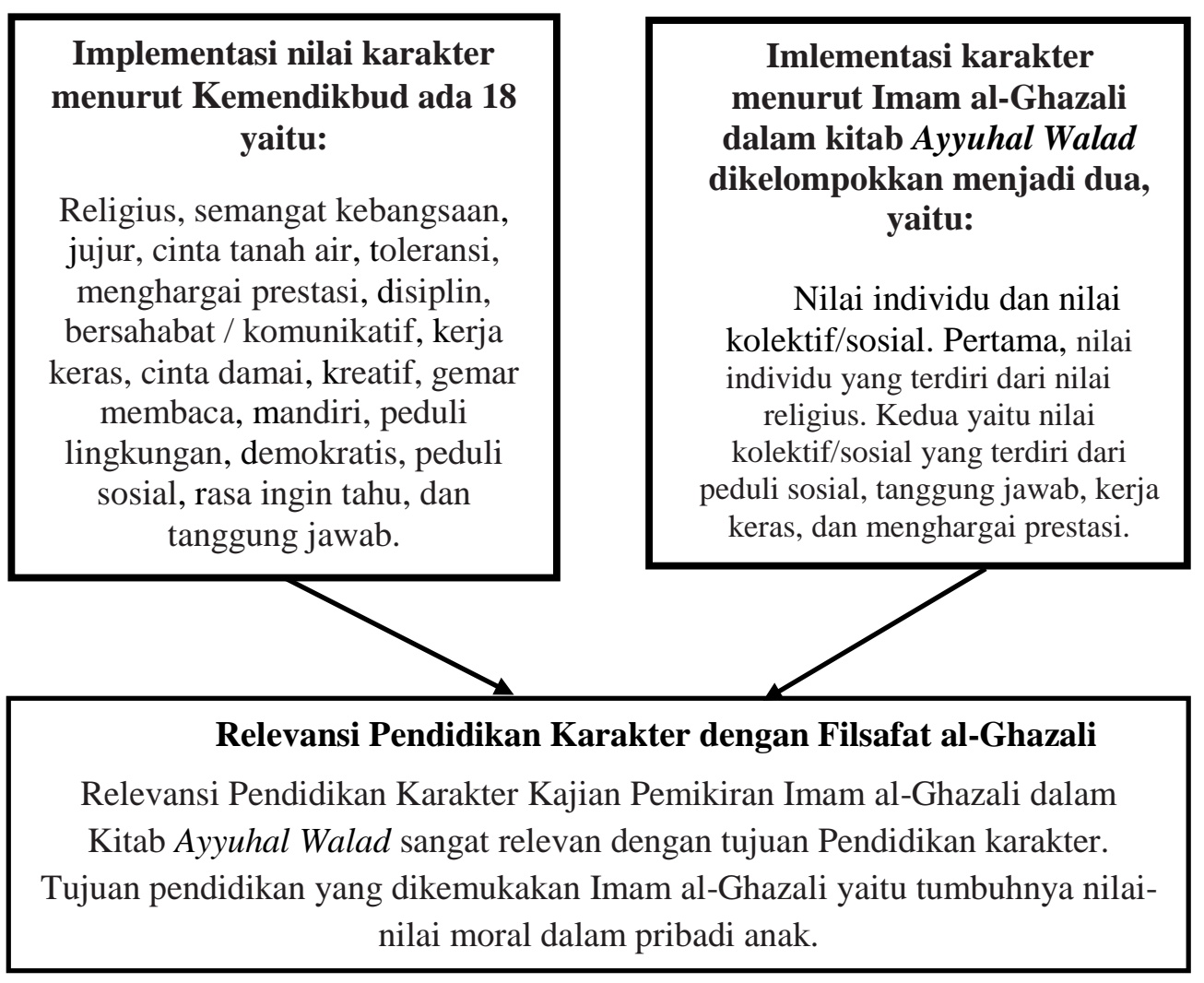

\section{Bagan 1. Relevansi Pendidikan Karakter dengan Filsafat al-Ghazali}

Salah satu kitab karangan Imam al-Ghazali yang tak kalah fenomenal di dunia pendidikan adalah kitab Ayyuhal Walad. Kitab tersebut membahas beberapa pokok bahasan tentang beragama. Salah satu yang menarik dalam

\footnotetext{
${ }^{22}$ Munir, Mulham, Abdul, Mencari Tahun dan Tujuh Jalan Kebenaran, (Jakarta: BumiAksara, 1991), 44
} 
pembahasan kitab ini adalah tentang konsep pendidikan akhlak untuk menjadikan manusia yang berkarakter. Kitab Ayyuhal Walad berisikan tentang adab dalam belajar. Sehingga dalam pembahasan kitab Ayyuhal Walad dapat membantu dalam memperbaiki pendidikan karakter saat ini yang mulai mengalami kemerosotan. Serta dapat memberikan sumbangsih dalam Pendidikan Agama Islam. Berikut akan dijelaskan relevansi pendidikan karakter dengan filsafat al-Ghazali.

Konsep pendidikan karakter yang ditawarkan oleh Imam al-Ghazali dalam Kitab Ayyuhal Walad adalah lebih pada sikap bagaimana karakter seorang muslim atau seorang hamba dalam berperilaku, baik kepada Tuhan, diri sendiri, orang lain dan lingkungan sekitarnya. ${ }^{23}$ Karena pada dasarnya pendidikan karakter tidak hanya mengajarkan mana yang benar dan mana yang salah kepada peserta didik, tetapi juga menanamkan kebiasaan (habituation) tentang yang baik, sehingga peserta didik paham, mampu merasakan, dan mau melakukannya. Dengan demikian pendidikan karakter mempunyai misi yang sama dengan pendidikan akhlak atau pendidikan moral. ${ }^{24}$

Pendidikan Akhlak merupakan inti dari pendidikan karakter. Akhlak mengarahkan pada perilaku yang berkarakter. Akhlakul karimah adalah tatkala perilaku manusia mengikuti aturan Islam dalam setiap aspek kehidupan, sebagaimana terimplikasi dalam hadits 'Aisyah ra yang artinya "Akhlak Rasulullah Saw adalah al-Qur'an". ${ }^{25}$ Konsep pendidikan al-Ghazali dalam kitab Ayyuhal Walad sangat relevan dengan pendidikan karakter saat ini. Sehingga cukup relevan jika pendidikan karakter Imam al-Ghazali diaplikasikan dalam pendidikan Islam di Indonesia sekarang. Walaupun pendidikan karakter memiliki proses panjang, namun ibarat pohon yang ditanam dengan kesabaran dan peliharaan yang baik, maka pohon akan subur dan baik buahnya. Karena untuk mencapai dan mewujudkan kehidupan yang berkarakter baik bukanlah dengan cara instan, namun butuh kesabaran dan keseriusan.

\footnotetext{
23 Al-Ghazāli, Ayyuhā al-walad, Misteri Ilmu Nafie' (Pen. Abu Tsania), (Jombang: Daru alHikmah, 1991).

${ }^{24}$ Marzuki, Pendidikan Karakter Islam, (Jakarta: Bumi Aksara, 1991).

${ }^{25}$ HR. Muslim
} 
F. Kesimpulan

1. Karakter merupakan perpaduan antara moral, etika, dan akhlak. Moral lebih menitikberatkan pada kualitas tindakan, perbuatan, atau perilaku manusia. Sebaliknya, etika memberikan penilaian tentang baik dan buruk, berdasarkan norma-norma yang berlaku dalam masyarakat tertentu, sedangkan akhlak tatanannya lebih menekankan bahwa pada hakikatnya dalam diri manusia itu telah tertanam keyakinan di mana keduanya (baik dan buruk) itu ada. Oleh karena itu, pendidikan karakter dimaknai sebagai pendidikan akhlak, pendidikan nilai, pendidikan moral, dan pendidikan budi pekerti, yang tujuannya mengembangkan kemampuan siswa untuk memberikan keputusan baik-buruk dan mewujudkan kebaikan itu dalam kehidupan sehari-hari dengan sepenuh hati.

2. Pendidikan karakter kajian pemikiran Imam al-Ghazali dalam kitab Ayyuhal Walad mencakup dua nilai yakni nilai individu yang meliputi karakter religius dan nilai kolektif atau sosial yang meliputi karakter peduli sosial, tanggung jawab, kerja keras, menghargai prestasi.

3. Relevansi Pendidikan Karakter Kajian Pemikiran Imam al-Ghazali dalam Kitab Ayyuhal Walad sangat relevan dengan Pendidikan Karakter. Tujuan pendidikan yang dikemukakan Imam al-Ghazali memiliki relevansi dengan tujuan pendidikan karakter yaitu tumbuhnya nilai-nilai moral dalam pribadi anak.

\section{Daftar Putaka}

Al-Ghazali. Ihya’ Ulum ad-Din, Beirut: Dar Ibnu Hazm, 2005. , Ihya' Ulum al-Dien, Jakarta: Fauzan, 1983. , Al-Munziq min al-Dhalal, Beirut: Maktabah al-Sya'ibah, 1960. , Ayyuhā al-walad, Misteri Ilmu Nafie’ (Pen. Abu Tsania), Jombang: Daru al-Hikmah, 2008.

Al-Madjidi. Konsep Pendidikan Para Filosof Muslim, Yogyakarta: Al-Amin, 1997. Arismantoro, Tinjauan Berbagai Aspek Character Building Bagaimana Mendidik Anak Berkarakter, Yogyakarta: Tiara Wacana, 2008. 
Daudy. Achmad, Kuliah Filsafat Islam, Jakarta: Bintang Bulan, 1986.

Depdiknas. Undang-Undang No. 20 tahun 2003 Sistem Pendidikan Nasional, www.depdiknas.go.id, 2003.

Hidayatullah, M. F., Guru Sejati: Pengembangan Insan Berkarakter Kuat dan Cerdas, Surakarta: Yuma Pustaka, 2010.

Kemendiknas. Membangun Budaya dan Karakter Bangsa, Jakarta: Puskur, 2010. Koesoema, A. D., Pendidikan Karakter: Strategi Mendidik Anak di Zaman Global, Jakarta: Grasindo, 2007.

Lickona, Thomas. Educating for Character: How Our School Can Teach Respect and Responsibility, New York: Bantam Books, 1991.

Marzuki. Pendidikan Karakter Islam, Jakarta: Bumi Aksara, 2015.

Megawangi, Ratna. Pendidikan Karakter: Solusi yang Tepat untuk Membangun Karakter Bangsa, Jakarta: Penerbit IHF [Indonesia Heritage Foundation], 2004.

Munir, M. A., Mencari Tahun dan Tujuh Jalan Kebenaran, Jakarta: Bumi Aksara, 1991.

Samani, M. H., Konsep dan Model Pendidikan Karakter, Bandung: Remaja Rosda karya, 2013.

Shariati, Ali, Tugas Cendekiawan Muslim.Terj. M. Amien Rasi. Jakarta: Srigunting, 1996.

Shihab, Muhammad Quraish, Membumikan al-Qur'an, Bandung: Mizan, 1992.

Sudrajat, Ajat. "Mengapa Pendidikan Karakter?.” Jurnal Pendidikan Karakter, Vol I, Nomor 1 (2011).

Sulistiwati, Endah, Implementasi Kurikulum Pendidikan Karakter, Yogyakarta: PT Aji Citra Parama, 2012.

Suyata, Pendidikan Karakter dalam Perpektif Teori dan Praktik, Yogyakarta: UNY Press, 2011.

Tim Bahasa Pustaka Agung Harapan, Kamus Cerdas Bahasa Indonesia Terbaru, Surabaya: CV Pustaka Agung Harapan, 2003.

Undang-undang Nomor. 20 tahun 2003, Tentang Sistem Pendidikan Nasional dan Penjelasannya, Yogyakarta: Media Wacana Perss.

Zubaedi, Desain Pendidikan Karakter, Jakarta: Kencana, 2012. 